\title{
Why Churches Need Free-riders: Religious Capital Formation and Religious Group Survival
}

\author{
Michael McBride* \\ Department of Economics \\ University of California, Irvine
}

This version: 21 August 2007

\begin{abstract}
According to the prevailing paradigm, religion thrives when groups overcome the free-rider problem in the production of religious goods. This paper argues, however, that religious organizations need free-riders in a dynamic setting. If individuals' contributions to congregations increase as their exposure to religion increases, then congregations that allow potential recruits to free-ride temporarily may increase their future memberships. Indeed, if religious capital only forms after exposure to the religious good, then free-riders comprise a risky but necessary investment by the church. Strict churches screen out riskier investments yet still allow some free-riding. This explanation yields predictions consistent with the empirical evidence.
\end{abstract}

JEL Classifications: Z12, L31.

Keywords: religion, free-riding, religious capital.

*3151 Social Science Plaza, Irvine, CA, 92697-5100, mcbride@uci.edu. I thank friends, colleagues, participants of the 2006 Association for the Study of Religion, Economics, and Culture (ASREC) Conference, and participants of the UC Riverside Economic Theory Seminar for valuable comments. 


\section{Introduction}

Economic theories of religious organization derive primarily from Iannaccone's $(1992 ; 1994)$ theory of strict churches. ${ }^{1} \quad$ Iannaccone notes that because religious goods are collectively produced, their production is susceptible to free-riding. Because churches have difficulty identifying and excluding free-riders directly, they resort to an indirect method to obtain high contributions from their members. By requiring members to comply with easy to observe yet costly stigmatizing and peculiar behaviors, only the most committed individuals will join or stay, while those more likely to free-ride will not join or stay. Strict churches with these requirements should have fewer free-riders, higher contributions, and higher quality religious goods than non-strict churches. A seemingly irrational requirement by strict churches can thus be understood in the context of collective production as a rational way to screen out free-riders and thereby thrive in the religious marketplace. ${ }^{2}$

The power of this stigma-screening theory is evident in its ability to explain the empirically observed vitality of strict churches (Kelley 1972; Iannaccone 1994). Members of strict churches contribute more financially on average to their churches (e.g., Iannaccone 1994; Hoge et al 1996; Olson and Perl 2001). Furthermore, contributions in strict churches are less skewed than in other churches so that the higher average contributions in strict churches is due to everyone contributing more and not just a smaller proportion of very large contributors (Iannaccone 1994; Olson and Perl 2005). These two facts imply that strict churches have relatively fewer free-riders than other churches, and, in turn, help explain why strict churches grow faster than non-strict churches (Iannaccone, Olson, and Stark 1995). Because the screening out of free-riders is difficult or impossible to observe, these facts do not prove per se that stigma-screening is the mechanism by which strict churches succeed. Nonetheless, the stigma-screening theory has become a key component of the new religious

\footnotetext{
${ }^{1}$ The economic research on religious organization is one of many areas of the research on the economics of religions. E.g., an individual's utility may depend on actions related to afterlife benefits (e.g., Azzi and Ehrenberg 1975) or be due to a rational addiction to religion (e.g., Iannaccone 1990); religious suppliers may behave as rent-seeking monopolists (e.g., Ekelund et al 1996) or as producers of club goods (e.g., Iannaccone 1992; 1994); and regulations may inhibit both religious pluralism and religious participation. (e.g., McBride 2007).

${ }^{2}$ To be precise, those groups that thrive are strict (e.g., Seventh-day Adventists) but not too strict (e.g., Branch Davidians), as too much strictness creates high levels of tension with the surrounding environment and can lead to the demise of the group.
} 
economies paradigm in the sociology and economics of religion (e.g., Stark and Finke 2000 Ch.6; Iannaccone 1998).

Other evidence, however, suggests that the stigma-screening theory is incomplete. Strict churches still have free-riders. For example, while there are roughly 6.6 million Jehovah's Witnesses worldwide who actively preach door-to-door each month, there are almost the same number of individuals who attend Jehovah's Witnesses meetings but do not actively preach. ${ }^{3}$ Any stigma-screening, if at work at all, clearly falls far short of eliminating all freeriding. It is also true that many successful religious groups are very welcoming to individuals who contribute little to the group; in fact, those free-riders might be the focus of costly and vigorous efforts by church members. Megachurches, for example, are growing in number and influence yet appear to have memberships with large proportions of free-riders who are actively courted. ${ }^{4}$ Why do churches - even strict ones - allow or even welcome free-riding? Does the presence of welcomed free-riders in strict churches undermine the stigma-screening theory? That strict churches have free-riders could simply result from imperfect screening, but the fact that known free-riders can be the focal point of very costly church efforts is more problematic for the theory because it implies that strict churches see the presence of free-riders as consistent with their mission and purpose.

This paper argues that strict churches - indeed, all churches - need free-riders of a certain form. The argument stems from the notion of religious capital, which is an individual's set of skills, experience, knowledge, and familiarity tied to a specific religious group's doctrine, structure, and norms (Iannaccone 1990). As religious capital grows, so does an individual's marginal value of participation and her willingness and ability to contribute to the group. By allowing some individuals, who are not yet willing to contribute, to consume the religious goods, the church makes an investment in their religious capital with the hope that they contribute in the future. Indeed, because contributors are not born but must be produced, a church must allow a degree of free-riding to survive over time.

\footnotetext{
${ }^{3}$ The 2005 Report of Jehovah's Witnesses (http://www.watchtower.org/statistics/worldwide_report.htm) lists 6.6 million members worldwide. Other official statistics can be obtained from the annual Yearbook of Jehovah's Witnesses Statistics. According to Stark and Iannaccone (1997), the official statistics undercount by nearly a half the number of individuals who self-identify as Jehovah's Witnesses. Membership statistics only count those, denoted "publishers," who actively preach a certain number of hours a week.

${ }^{4}$ See Thumma, Travis, and Bird (2005) and Thumma (2006) for basic information about megachurches.
} 
This logic complements Iannaccone's stigma-screening theory. A church's investment in members is risky because not all individuals who consume the good become contributors. The investment is also costly because the free-riders consume church resources and decrease average contributions, thereby decreasing the quality of the church's religious services. Hence, a church does not want just anyone to free-ride; it prefers to invest in individuals with higher expected returns on the investment. By increasing the cost of membership, the church screens out those less likely to form high religious capital. This explanation is a dynamic revision of the stigma-screening theory. Whereas the original theory states that requiring members to undertake stigmatizing behavior screens out free-riders, the revision proposed here states that the behavioral requirements screen out those more likely to remain free-riders.

Earlier research using a "rational choice" approach to religion ${ }^{5}$ acknowledges that accommodating potential contributors serves a dynamic purpose, yet it has not constructed a general theory of free-riding and religious capital formation. Miller (2002) uses a "strategic management perspective" in claiming that "Reducing the demands placed upon potential customers eases them into a religious organization" thereby fostering membership growth (445). Yet, he does not connect his claim directly to the process of religious capital formation. McBride (forthcoming) identifies many of the practices and policies of the Church of Jesus Christ of Latter-day Saints (Mormon) as investments in less-committed members' religious capital but does not generalize his idea. Thumma (2006), von der Ruhr and Daniels (2006), and von der Ruhr and Reynolds (2006) discuss how free-riders comprise the pool of those being evangelized in megachurches but also do not generalize their idea. Unlike the earlier work, this paper explicitly and formally combines dynamic religious capital formation with static stigma-screening. It explains why churches need not eliminate free-riding

\footnotetext{
${ }^{5}$ Warner (1993) characterizes the rational choice approach to religious as a new paradigm. See Iannaccone (1995a; 1995b), Ellison (1995), Chaves (1995), Demerath (1995), and the essays in Young (1997) for descriptions, defenses, and critiques of the rational choice approach. Iannaccone (1998) reviews the work by economists. Not all researchers fully agree with the new view. To some, the once dominant secularization hypothesis, exemplified by Berger's (1967 [2000]) Sacred Canopy thesis which predicted a decline in religion with modernization, has transformed into a neo-secularization theory (Yamane 1997), which, according to a popular undergraduate text, is less a predictive theory than a useful descriptive concept about the many ways religion changes in response to modernization (Roberts 2004). Others hold fast to a traditional secularization hypthesis (e.g., Bruce 2002).
} 
so much as they must strategically manage it by maintaining a certain type of heterogeneity in the membership. Stigma-screening, which homogenizes membership in a different dimension, serves a complementary purpose.

After briefly reviewing the original theory and empirical evidence on free-riding in strict and non-strict churches in Section 2, Section 3 presents a verbal description of the new theory and how it relates to the original theory. Section 4 then presents a formal game-theoretic model of free-riding and religious capital formation. Similar to the original theory, the new theory predicts the empirical facts mentioned earlier, i.e., that strict churches will have a smaller proportion of free-riders than easy-going churches and that contributions in strict churches will be less skewed than in easy-going churches. Yet, it also makes a new prediction that both strict and non-strict churches will welcome certain types of free-riders. Section 5 concludes with a brief discussion of the key insights.

\section{The Original Theory and Empirical Evidence}

The free-rider problem arises in religion because of the nature of religious goods and services. While some private religious goods, such as the communion with deity associated with prayer, meditation, and other personal devotional activities, are produced and consumed by an individual, many goods provided by religious groups are produced collectively. The financial contributions of many people are needed to build and maintain a meetinghouse and fund various religious activities such as social events or proselytizing, clergy salaries, and more. Other contributions in time and emotional effort add vitality to hymn singing at church meetings, build meaningful bonds among members, reinforce members' religious beliefs, and may even help reduce certain financial obligations (e.g., members can perform basic maintenance on the building to reduce operational costs) so that funds can be spent for other activities. In short, the more people contribute in time, money, and effort, the more and better the goods and services provided by the church for all members.

Notice, however, that if an individual can consume these many benefits without "paying" for them, then it is rational for her to free-ride on others' contributions. ${ }^{6}$ If this incentive

\footnotetext{
${ }^{6}$ It is useful here to clarify what I mean by free-riding. One definition of free-riding is consuming while contributing zero to production-literally riding for free. Of course, many people, so-called "cheap-riders,"
} 
exists for many members and if they all free-ride, then the church will receive relatively low contributions and, consequently, produce low quality religious goods and services. Of course, if the church can monitor contributions at low cost, then it can identify free-riders and deny them membership and access to the church's goods and services. In other words, if the church can condition membership on observable contributions, then it can prevent free-riders from riding for free. Unfortunately, it is difficult to measure many types of contributions. Full effort in hymn singing and friendshipping is difficult to identify, as is the fairness of one's financial donations.

Iannaccone $(1992 ; 1994)$ recognized that churches are limited in their ability to identify, and hence exclude, free-riders, and he argued that strict churches have developed another method to limit free-riding. The stigmatizing and often peculiar behaviors required by strict churches, such as wearing distinctive clothing, abstaining from certain foods or drinks, and moving to a commune, all raise an individual's cost of membership by raising the cost of secular activities. Because these behaviors are easier to observe than other actions associated with religious effort, a church can condition membership and access to the church's goods on compliance with these codes of conduct. These behavioral requirements limit freeriding if the associated costs are relatively lower for religiously committed individuals than for free-riders. By sufficiently raising the cost of membership, the free-riders will screen themselves out of the group, and as long as the cost is not too high, the committed types will screen themselves into the group. If successful, this process allows the church to gain a membership of highly committed individuals who make large contributions thereby fostering the production of high quality religious goods. Though this approach is costly to members and overall inefficient due to the costs that do not directly increase production, the members will comply with the stigmatizing behaviors if the religious goods produced via the stigmascreening are sufficiently better than those produced without stigma-screening.

This logic yields multiple hypotheses. First, because strict churches should have propor-

consume while contributing very small but non-zero amounts. Any definition assumes a threshold below which a contribution is considered free-riding. This threshold is not simply a one-to-one consumption-tocontrtibution ratio because even high contributors in the presence of positive externalities receive benefits that far exceed their individual contributions. In the model below, free-riding will be explicitly defined, but for the sake of discussion, I assume that such a meaningful threshold exists. 
tionally fewer free-riders, they should receive higher average contributions (both monetary and non-monetary) from their members. Second, because the screening process should yield more homogenous and highly committed memberships within strict churches, the skewness of the distribution of members' contributions should be lower in strict churches than in easygoing churches. A third prediction is that strict churches should provide larger benefits to their members than other churches.

Testing these predictions requires first the identification of strict churches. Table 1 depicts Stark and Finke's (2000) classification of some American religious groups by strictness. Twenty groups are partitioned into six niches of decreasing strictness, the top two or three of which could be considered strict. (Please note that the term strict in this paper refers to strictness generally speaking and not the specific niche labelled "strict" in Table 1.) Others have attempted similar classifications (e.g., Iannaccone 1994), and there appears to be general consensus about which churches are strict and which are not.

Even with strict churches identified, it is difficult to directly test the predictions about members' contributions because many types of contributions, such as time and effort, are difficult to measure. Monetary contributions are easier to measure, and if monetary and non-monetary contributions are positively correlated, then monetary contributions are a good proxy for overall contributions. For these reasons, much prior research on religious free-riding has focused on financial contributions. Consistent with the first and second predictions above, this work finds that members of strict churches do contribute more financially to their churches on average than members of other churches and that contributions are less skewed in strict churches (Iannaccone 1992, 1994; Hoge et al 1996; Olson and Perl 2005).

I will not review this earlier work in detail but will instead provide a snapshot of the evidence using data from the General Social Survey (GSS). Table 2 column (a) presents the average yearly contribution amount for each of 13 religious groups as reported in the GSS from 1987-1989. For ease of comparison, the groups are partitioned in strict, not strict, and other in a manner consistent with the classification in Table 1, and they are ordered by average contributions within each partition. These data indicate that members of strict groups do tend to make, on average, larger contributions. In fact, the lowest average contributions among the strict churches belongs to Jehovah's Witnesses, and they are well 
known for making large non-monetary contributions (e.g., time spent witnessing). Column (c) shows that members of strict churches tend to give larger percentages of their incomes as well. Columns (b) and (d) show that the skewness in yearly contributions and percent of income contributed both tend to be lower in strict churches than in non-strict churches. ${ }^{7}$

The third prediction, that strict churches provide higher quality religious benefits, is not possible to test directly. As Olson and Perl (2005: 126) state, "Such benefits are often psychic (e.g., the inspiration one receives from hearing a stirring sermon) and extremely difficult to measure with any accuracy." Some insight, however, can be gleaned from the 1988 GSS, which includes a question asking the respondent to grade how well her church meets her spiritual needs. As shown in Table 3, members of strict churches generally report higher self-reported grades than members of easygoing churches. Because these data do not constitute a random sample (i.e., people can select themselves into religious groups) and we have a small number of observations for many denominations, they are only suggestive. Yet, they do indicate that members of strict churches are more satisfied with their churches, which, in turn, suggests that they believe their churches provide them meaningful benefits.

\section{A Theory of Stigma-screening with Religious Capital Formation}

Taken together, the above data provide compelling evidence in support of the stigmascreening theory. Strictly speaking, the evidence does not prove that the stigma-screening process is at work. It establishes that some of the outcomes predicted by the stigmascreening process are in fact observed, but it does not distinguish the stigma-screening process from other processes that could generate the same outcomes. This realization is not necessarily a shortcoming of the theory but can instead be a reflection of the realities and difficulties of data collection and interpretation. Yet, other evidence suggests there are other processes at work that force a rethinking of the theory.

Although the distribution of contributions is less skewed in strict churches than in non-

\footnotetext{
${ }^{7}$ Olson and Perl (2005) explain that comparing skewness between strict and easygoing churches is more appropriately done at the congregation, not denomination, level. That level, of course, cannot be analyzed with GSS data. But because I am interested in only illustrating the facts, the denomination level data are sufficient for my purposes.
} 
strict churches, contributions are still skewed in strict churches. Iannaccone (1997) explains that skewness should be expected given natural variation in percentage giving rates, variation in income levels, and a weak correlation between income and contribution rates, but the skewness is also likely related to the existence of free-riders. Some members are high contributors with strong religious convictions, while others are free-riders to varying degrees. Who are these free-riders, and why does the stigma-screening process not screen them out of the group?

Another fact is that churches, even strict ones, are often very friendly to certain freeriders. Churches often keep their facilities open for strangers to enter and use without expecting anything in return. Churches happily welcome large crowds of infrequent attendees during holiday services even when those individuals commonly known to contribute little to the church. Earlier research identifies two insightful cases of this general phenomena in very successful religious groups: the Church of Jesus Christ of Latter-day Saints (LDS or Mormon) and megachurches.

The LDS Church certainly meets the definition of a strict church with its many behavioral standards. LDS are to abstain from alcohol, tobacco, coffee, and tea, as well as abstain from pre- or extra-marital sexual relations. Consistent with the stigma-screening theory, LDS contribute, on average, a very high percent of their income to the Church in tithes and in time and energy in official and unofficial Church activities. The Church's ability to amass such resources fuels its fast membership growth; it is one of the fastest growing denominations in the United States and is growing even faster worldwide. Yet, as shown by McBride (forthcoming), the LDS Church has free-riders, too. Some LDS attend and benefit from Church meetings and receive various services, such as home visits, while not contributing much money, time, or effort. Moreover, local Church leaders direct many efforts and easyto-exclude services to those very members who they know are not contributing much. For example, a local LDS bishop (pastor) knowing full well that an individual is contributing little to the Church will channel to that individual formal home visits, informal friendshipping, and other services that are costly in time and effort for other members.

Megachurches, i.e., congregations which average more than 2000 weekly adherents, pose an additional puzzle. There are over 1200 megachurches in the United States; roughly half 
of them average more than 3000 attendees per week, and roughly $16 \%$ average over 5000 per week (Thumma, Travis, and Bird 2005). Their sheer size suggests that weekly meetings are a type of spectator entertainment, yet this characterization is misleading. It is difficult to label a megachurch strict or non-strict because they often preach orthodox beliefs and place large demands on highly committed members while simultaneously requiring little or nothing from a large percent of attendees. Members are encouraged to participate in a number of other smaller group interactions with other attendees, thereby building stronger bonds and encouraging commitment. Those who do not are actively evangelized to foster higher commitment. This strategy is currently very successful, as there are nearly double the number of megachurches today than there were five years ago.

Why are churches so welcoming to free-riders? At this point we should recognize that free-riders can be meaningfully partitioned into different categories. One category is those individuals who exemplify the spirit of the term free-rider-adult members who attend church meetings and consume church services, yet contribute little financially or otherwise to the production of religious goods. Another category is new members and potential members who are the beneficiaries of tremendous amounts of fellowshipping and proselytizing efforts, but who have not yet developed the skills necessary to contribute in various ways. For example, their religious knowledge is too limited to lead youth groups and religious lessons. A third category is children who contribute no money and very little time and effort. They are the beneficiaries of the efforts of others, particularly adults.

Still other categories could be defined, yet the last two are instructive. New and potential members and children are welcomed at churches even though their contributions are small. Long-standing adult members may enjoy their presence in the congregations, as they add a type of vitality to church meetings. However, more important to the group itself is that these individuals have the potential to become large contributors in the future even though their contributions today are small. As they repeatedly experience and consume religious services, they build ties with other church members and learn church doctrines and norms. In other words, they form religious capital (Iannaccone 1990).

The term capital as used by economists refers to a good that is produced not for consumption directly but instead for the production of another good that is consumed. Machines 
and equipment are examples of physical capital. Economists have also recognized the importance of human capital that resides within the individual, such as education and job training used to produce other goods, and social capital that consists of social ties and bonds that foster trust and cooperation. Religious capital is a type of human and social capital that increases an individual's productivity and consumption value of religious goods. On the production (supply) side, an individual's experience and knowledge tied to a particular church increase her ability to produce religious goods associated with that church. A churchgoer who knows the hymns improves the quality of the hymn singing more than a churchgoer who does not know the hymns, and a teacher who has extensive knowledge of church doctrines and practices should, all else equal, provide better instruction than a teacher who does not know. Religious capital also influences consumption (demand) in that it directly increases the consumption value of the religious goods for the holder of the religious capital. Familiarity with doctrines and practices improves the symbolic quality of religious services, social bonds strengthen the feeling of community within the group, and increased religious conviction increases the sense of purpose associated with all of the above. ${ }^{8}$

A key assertion of this paper is that religious capital influences the incentive to free-ride. Because religious capital increases a churchgoer's consumption value of religious services (the demand side), it also increases that churchgoer's individual marginal benefit of donating time, money, and effort towards the production of those services. An increase in religious capital decreases the incentive to free-ride, so an individual's incentive to free-ride diminishes over time as her religious capital grows. Children form religious capital as they experience the religious goods, as do new members as they are socialized into the new religion. ${ }^{9}$ Thus, although these individuals contribute little to the production of religious goods and services today, they might very well become significant contributors in future months or years. Even the long-term member free-riders can also form religious capital as they continue their reli-

\footnotetext{
${ }^{8} \mathrm{I}$ here argue that religious capital increases both religious supply and religious demand. Others have depicted religious capital as influencing religious supply not demand (e.g., Sherkat and Ellison 1999), yet a careful reading of Iannaccone's (1990) article reveals that Iannaccone envisioned demand side effects of religious capital. For example, he wrote, "Religious capital ... enhances the satisfaction one receives from participation in that religion..." (299).

${ }^{9}$ Religious capital should be distinguished from other types of human and social capital that enhance secular opportunities, such as literacy or business connections, that might also form as a result of religious participation but that do not directly serve to tie the person to the religious group (see Fan forthcoming).
} 
gious participation. Though not contributors today, they could become contributors in the future.

From an organization's viewpoint, allowing individuals to free-ride is necessary in order to produce high quality religious goods because individuals are not born with religious capital. Individuals must develop the capital as they participate in various group related activities. Thus, if individuals only contribute large amounts when they have religious capital, then they must first experience and consume the religious goods before they become contributors. This necessity puts the church in a paradoxical position. To produce high quality religious goods and services, it must limit free-riding, but to develop the high contributors necessary for a high quality product, it must also allow free-riding. Moreover, the church must continually replenish its stock of high religious capital members over time to maintain its production of high quality products. If the group fails to produce high capital individuals, contributions will decline, the quality of its product will decline, and it will be driven out of the religious marketplace.

A church can partially avoid this difficulty by recruiting individuals from churches with easily transferable religious capital, yet with easily transferable religious capital, it might be hard to retain members. I suggest here that actual churches instead survive over time by producing the religious capital themselves. They do this by maintaining both high and low capital individuals in their membership, or, to put differently, by maintaining memberships with both contributors and free-riders. High capital individuals provide core strength and valuable resources, while free-riders provide a pool of future contributors. As free-riders form their religious capital, they become high capital, high contributing members in the future. Because of population movement, eventual mortality, and other forces, the congregation will eventually lose its high capital members. To survive, the group must replace them with newly formed high religious capital individuals, and to do this, the group must maintain a pool of potential future contributors.

According to this explanation, free-riders comprise a costly investment by the church. The very presence of the free-riders places a drain on resources, thereby decreasing the quality of the religious goods. Yet, if religious capital formation is necessary to produce contributors, then even if the church can identify free-riders, it may still have to let them remain in the 
group. Indeed, the more religious capital is necessary for a person to contribute, the more exposure to the religious goods are required for that person to form sufficient capital to be willing to contribute.

This very logic does not undermine the stigma-screening logic although it might appear to do so on the surface. The stigma-screening logic posits that strict churches want to screen out free-riders instead of welcome them. However, a church's investment in free-riders is not only costly; it is also risky because not all individuals who participate religiously will form high religious capital. This suggests that a religious group does not want just anyone to join. Instead, it would prefer to have join only those individuals who are more likely to form high religious capital. If the group could identify these individuals, then it could actively recruit them, thereby improving the return on its investment. The children of contributing members, for example, should have a higher chance of forming high capital than other children because families consume many religious goods together and religious ideals and norms can be reinforced at home. This explains why churches actively recruit the children of adult members and devote resources towards the production of their religious capital.

Focusing on children of adult members is not the only method a church can use to improve the return on its investment. Stigma-screening can still fulfill a valuable role. If there was no cost to membership, then anyone would want to join and free-ride on others' contributions. With some high capital types, the group would survive, but it would have a lower quality religious good than it would without those free-riders. While some of the free-riders would form high capital and become contributors, many would not form high capital and thus continue to free-ride. If by requiring all members to observe strict behavioral requirements the cost of membership becomes too high for some free-riders but not for those who are more likely to form high capital, then stigma-screening can increase the expected return on the group's investment. If an individual knows that there is a good chance she will form high religious capital and thereby greatly value her membership, then she will be willing to pay the cost of membership. The behavioral requirements allow individuals to sort themselves into and out of the religious group. Those more likely to form high religious capital will join or stay, while others will leave. 
A religious group allowing an individual to free-ride while she forms religious capital is akin to the group subsidizing her religious capital formation, but it differs from paying individuals to join without asking anything in return. If a church offered free religious goods but did not ask anything in return, then everyone, including those who will never form religious capital, would join because there were benefits without costs. Instead of offering only free benefits, strict churches also require all members to pay a cost associated with the stigmatizing behavior, and it is this cost that screens out those individuals less likely to form religious capital. Thus, a religious group that wants to increase the quality of its religious goods must still require all members to pay a cost, even if that cost is not directly productive.

Understanding how free-riding relates to religious capital implies a dynamic revision of Iannaccone's stigma-screening theory. Contributors are not born; they are instead produced through an investment by the church. Because they are a costly and risky investment, stigma-screening allows a church to screen out those individuals for whom the investment has a lower and less risky expected return. Stigma-screening thus increases the return on the church's investment in religious capital formation. Three specific predictions follow.

Proposition 1 Strict churches will have fewer free-riders than non-strict churches.

Proposition 2 The distribution of contributions will be skewed in both strict and non-strict churches, but it will be less-skewed in strict churches.

Proposition 3 Both strict churches and non-strict churches will have free-riders who are welcomed.

This first proposition follows from logic similar to the earlier stigma-screening theory. Behavioral requirements screen out some free-riders in the new theory just as they did in the original theory. Although the second proposition was implied by the original theory, it was not a key component of the theory. It now forms a key part of the new theory because having some free-riders implies skewness in contributions, and having fewer free-riders in strict churches implies less skewness in strict churches. The original stigma-screening theory 
did not have a specific prediction about the presence of free-riders in strict churches, yet this is a direct implication of the new theory in Proposition 3.

With this paper's core idea now described, a few points deserve mention. First, depending on the nature of the religious good, an individual's religious capital formation may only be possible if the individual contributes towards the good's production. Passively listening to a sermon or choir, for example, increases an individual's appreciation for the group's teachings and services and therefore increases an individual's religious capital. The value of private meditation, on the other hand, may increase only with lots of practice and effort. The distinction centers on the cost of participation that must be paid to produce the capital, but notice that this is directly related to the presence of the free-rider problem because it is related to the excludability of the good. While the first example requires essentially only the opportunity cost of time to consume what others produce, the second requires other efforts in addition to time. The benefits of meditation are naturally excluded from all but those who exert effort in meditating. For that reason, the theory presented here considers the second type of religious capital formation.

A second note is that the investment explanation proposed here differs in an important way from the investments undertaken by other organizations. Firms producing secular goods, for example, undertake various forms of investment. They borrow money to purchase equipment, thereby increasing the stock of physical capital. They also divert the time and efforts of productive employees towards training new employees instead of producing goods. A religious group's investment in its members' religious capital is, in principle, akin to these secular investments in that it is a costly action undertaken to improve future production. The important difference is that religious capital investment takes place in the context of collectively produced club goods with free-rider problems. The investment is not a direct cost but is instead an indirect result of allowing larger than desirable (in a static sense) free-riding which in turn reduces the actual quality and quantity of the club good.

A third note is that religious capital formation can - but does not have to-be understood in the framework of "rational addiction." Becker and Murphy (1988), for example, examine a model in which an individual's consumption of a good increases her "consumption capital" and thereby increases her consumption value of that good in the future. In their rational 
addiction setting, the individual may rationally choose to consume the good knowing full well the addictive effects it has on future utility. Addiction could instead be irrational (Tomer 2001) due to, for example, defective mental performance in evaluating consequences. Religious capital formation could also be coerced, as in the little child who prefers to not attend the religious meetings but succumbs to parental pressure and still forms the religious capital. The primary theory developed in this paper is amenable to each of these circumstances because it is in the group's interest to strategically allow free-riding whether or not the free-riders are rational choosers, boundedly rational, or coerced, etc. For concreteness, the model in the next section will consider rational addiction because Iannaccone (1990) originally framed religious capital in those terms.

\section{A Formal Model}

This section presents a formal model of stigma-screening with religious capital formation in a single religious group. It demonstrates in the logical cohesion of the theory verbally described above, and the propositions arise as equilibrium predictions of the model.

\subsection{Basic Model}

In each period $t, n \geq 3$ identical individuals are born (the identical assumption will be relaxed in Section 4.4). Each individual lives two periods, denoted childhood and adulthood. These labels are for expositional ease and should not be interpreted literally. In each period, each individual chooses whether or not to join a religious group and then, conditional on joining, whether or not to contribute to the production of the religious good.

Assume that there is only one religious group and that religious goods cannot be produced outside this group. The first assumption simplifies the analysis, ${ }^{10}$ while the second reflects the collective nature of religious good production.

Let $c_{i, t}^{b_{i}} \in\{0,1\}$ denote the contribution level chosen in period $t$ by individual $i$ who was born in period $b_{i}$. Then, $c_{i, t}^{b_{i}}=1$ signifies that individual $i$ born in period $b_{i}$ contributes

\footnotetext{
${ }^{10}$ If the number of groups was endogenous to the model, then groups would concern themselves with optimal group size. However, the main logic about religious capital formation and the necessity of free-riders would remain intact. The simplifying assumption of one groups allows for a focus on that key logic.
} 
in period $t$, while $c_{i, t}^{b_{i}}=0$ signifies $i$ born in $b_{i}$ does not contribute in $t$. Restricting to binary contributions simplifies the analysis; the key results can be obtained with continuous contributions.

Let $M_{t}, 0 \leq\left|M_{t}\right| \leq 2 n$, be the set of individuals alive at time $t$ that join in time $t$, and suppose their profile of contributions in time $t$ is $\left\{c_{j, t}^{b_{j}}\right\}_{j \in M_{t}}$. Then the religious good has a base value in time $t$ of

$$
f\left(\frac{1}{\left|M_{t}\right|} \sum_{j \in M_{t}} c_{j, t}^{b_{j}}\right)
$$

if $\left|M_{t}\right| \geq 2$ and 0 otherwise. The $\frac{1}{\left|M_{t}\right|} \sum_{j \in M_{t}} c_{j, t}^{b_{j}}$ term is the average of all members' contributions in period $t$. Assume that religious goods are increasing in average contributions, $f^{\prime}(\cdot)>0$.

Each individual $i$ born in $b_{i}$ maximizes her lifetime utility,

$$
U_{i t}=u_{i, b_{i}}^{b_{i}}+u_{i, b_{i}+1}^{b_{i}},
$$

where $u_{i, b_{i}}^{b_{i}}$ and $u_{i, b_{i}+1}^{b_{i}}$ are the single period utilities from childhood and adulthood.

The single period utility is a function of the good's base value, $i$ 's religious capital $k_{i, t}^{b_{i}}$ in $t$, and the contribution choices of the various individuals. Specifically,

$$
u_{i, t}^{b_{i}}=\left\{\begin{array}{cc}
k_{i, t}^{b_{i}} f\left(\frac{1}{\left|M_{t}\right|} \sum_{j \in M_{t}} c_{j, t}^{b_{j}}\right)-c_{i, t}^{b_{i}} & \text { if }\left|M_{t}\right| \geq 2 \\
-c_{i, t}^{b_{i}} & \text { otherwise. }
\end{array}\right.
$$

Note that $i$ 's religious capital only influences the value of her religious consumption and not the quality of the club good for others. A richer model would consider the impact of $i$ 's capital on religious production as well as consumption (e.g., an increase in $i$ 's religious capital could increase her ability to produce goods for others to consume). This addition would not substantively alter the main results because it would not fundamentally alter the decision making incentives of an individual who cares only about the costs and benefits of her own contribution decision. I leave it out to simplify the model.

Assume that every individual is born with the same religious capital $k_{1} \geq 0$. Also assume that the religious capital of each child who consumes the religious good in time $t$ will increase to $k_{2} \geq k_{1}$ in time $t+1$. An increase in capital from $k_{1}$ to $k_{2}$ is what we call religious capital formation in this model. The religious capital of those children who did not consume the 
religious good in time $t$ remains at $k_{1}$. I later relax the assumption that all religious good consumers become high religious capital adults.

\subsection{Religious Production and Religious Capital Formation}

Let us first consider a scenario in which the religious good cannot be excluded from the general membership and in which there is no membership cost to joining the religious group. This scenario is the simplest case that illustrates how free-riding exists in equilibrium.

Because no individual has a cost to join the group, every individual has a weakly dominant strategy to join, and we can focus solely on the contribution decision. I now show that there exists an equilibrium in which everyone joins the group, the high capital adults contribute, and the low capital children do not contribute. Let us derive the conditions for this equilibrium by looking at an adult's contribution decision assuming all others act according to the proposed equilibrium and then looking at a child's contribution decision again assuming others act according to the proposed equilibrium.

Note that if everyone abides this equilibrium then in each period $t$ there will be exactly half of the membership contributing; with $n$ adults and $n$ children, the proposed equilibrium has $n$ contributors and $2 n$ members of the group. When making her decision, the adult considers only the present period (her childhood decision is sunk). Given this behavior by the others, each adult joined as a child in period $t-1$ and so has high religious capital in time $t$. The high capital adult $i$ will contribute if the expected payoff of joining and contributing is greater than the expected payoff of not contributing:

$$
\begin{aligned}
k_{2} f\left(\frac{1}{2}\right)-1 & \geq k_{2} f\left(\frac{n-1}{2 n}\right) \Rightarrow \\
k_{2} & \geq \frac{1}{f\left(\frac{1}{2}\right)-f\left(\frac{n-1}{2 n}\right)} .
\end{aligned}
$$

This expression states that the adult only contributes if her capital $k_{2}$ is sufficiently high.

With this condition satisfied and assuming all others' abide the equilibrium, the child will contribute as an adult whether or not she contributes as a child. Thus, the child, when deciding whether or not to contribute, will only consider the relevant expected payoffs of her 
childhood period. Low capital child $i$ will not contribute if

$$
\begin{aligned}
k_{1} f\left(\frac{n+1}{2 n}\right)-1 & <k_{1} f\left(\frac{1}{2}\right) \Rightarrow \\
k_{1} & <\frac{1}{f\left(\frac{n+1}{2 n}\right)-f\left(\frac{1}{2}\right)} .
\end{aligned}
$$

Conditions (1) and (2) are, together, necessary and sufficient for the equilibrium to exist.

Claim 1 Suppose exclusion is not possible. If $k_{1}<\frac{1}{f\left(\frac{n+1}{2 n}\right)-f\left(\frac{1}{2}\right)}$ and $k_{2} \geq \frac{1}{f\left(\frac{1}{2}\right)-f\left(\frac{n-1}{2 n}\right)}$, then the partial free-rider equilibrium exists in which all children and adults join, all children have low religious capital and do not contribute, and all adults have high religious capital and contribute.

In words, if each child's religious capital is sufficiently small and each adult's religious capital is sufficiently large, then there exists an equilibrium in which children will freeride on the adults' contributions, and the adults will, consequentially, generate via their contributions the religious capital in the children necessary for the group to provide religious goods in the next period. Conditions (1) and (2) correspond directly to basic facts about religious capital formation. An individual's initial religious capital $k_{1}$ will be small before exposure to the club good, whereas individuals with high religious capital will highly value the religious goods. If the children have sufficiently low capital, then their marginal returns to contributing are very low, and they will not contribute. If adults have sufficiently high capital, then they are willing to contribute. The children are allowed to free-ride while they form religious capital. Of course, the children in the model correspond to any individuals in the real world who are free-riding while they develop their own religious capital, such as new members or even other members.

The denominator terms in the right hand sides of conditions (1) and (2) measure the equilibrium marginal productivities of the good's base value for adults and children, respectively. As this marginal productivity increases, $i$ is willing to contribute at more levels of religious capital. As $n$ approaches $\infty$, i's marginal productivity (the denominator) approaches 0 , thus driving the entire term towards $\infty$. This relationship is consistent with the idea that an individual's marginal productivity is smaller in larger groups. 
Notice what happens if the children are forbidden from joining. If in period $t$ the group decides to not allow the children to join because they are free-riders, then it might be possible to obtain contributions from all members. This yields a very high quality religious good in that period, but in the next period there are no high capital adults. Nobody will be willing to contribute, the good's base value will be 0 , and there would be no reason for individuals to join. The group would cease to exist. Allowing the children to free-ride is necessary for the group's survival.

\subsection{Exclusion of Free-riders and Religious Capital Formation}

We now examine whether the partial free-rider equilibrium exists when non-contributors could be costlessly identified and excluded from the religious group. Iannaccone's (1992; 1994) original work explains why religious groups have difficulty identifying and excluding free-riders, yet the costless exclusion case is an interesting theoretical one because, according to the spirit of the original stigma-screening logic, in it we might expect to see the least amount of free-riding. However, as will now be shown, the dynamic process of religious capital formation can be so important for a religious group to survive that it might allow free-riding even when it can costlessly identify and exclude free-riders.

To make the highest possible sanction, suppose that non-contributing children and noncontributing adults cannot consume the good, and also that any child who does not contribute as a child cannot consume the good as an adult even if she contributes as an adult. In this equilibrium, each adult has high capital and the base value of the good is $f(1)$ because everyone contributes. A high capital adult receives payoff 0 if she deviates by not contributing, while she receives $k_{2} f(1)-1$ by contributing. Thus, she will contribute if

$$
k_{2} \geq \frac{1}{f(1)}
$$

The child's payoff to not contributing is 0 today but also 0 tomorrow because she would not be allowed to join. Thus, her payoff to contributing must now consider both periods.

If $k_{2} \geq \frac{1}{f(1)}$, then she will contribute as an adult only if she contributes as a child. Thus, the payoff she considers when making her contribution choice is $k_{1} f(1)-1+k_{2} f(1)-1$. 
This payoff is greater than 0 when

$$
k_{1} \geq \frac{2}{f(1)}-k_{2}
$$

If $k_{2}$ is sufficiently large, then the right hand side will be less than $k_{1}$, and the full contribution equilibrium will exist. However, if $k_{2}$ is large but not too large and $k_{1}$ is small, then this equilibrium will not exist. In effect, because the utility of consumption is due in part to religious capital and not just contributions, exclusion will not work if the capital is too small.

Yet, the partial free-rider equilibrium will exist in this scenario. Because excluding the good from non-contributing high capital adults may help foster contributions, assume the group does so. Now, the adult will be willing to contribute if

$$
\begin{aligned}
k_{2} f\left(\frac{1}{2}\right)-1 & \geq 0 \Rightarrow \\
k_{2} & \geq \frac{1}{f\left(\frac{1}{2}\right)} .
\end{aligned}
$$

The child will join but not contribute if

$$
\begin{aligned}
k_{1} f\left(\frac{n+1}{2 n}\right)-1 & <k_{1} f\left(\frac{1}{2}\right) \Rightarrow \\
k_{1} & <\frac{1}{f\left(\frac{n+1}{2 n}\right)-f\left(\frac{1}{2}\right)} .
\end{aligned}
$$

Claim 2 Suppose exclusion is costless. The partial free-rider equilibrium exists if $k_{1}<$ $\frac{1}{f\left(\frac{n+1}{2 n}\right)-f\left(\frac{1}{2}\right)}$ and $k_{2} \geq \frac{1}{f\left(\frac{1}{2}\right)}$.

A simple example demonstrates when the PFR equilibrium exists at the same time the full contribution equilibrium does not. Suppose $k_{1}=0$. Using our analysis above, the full contribution equilibrium exists if $k_{2} \geq \frac{2}{f(1)}$, and the PFR equilibrium exists if $k_{2} \geq \frac{1}{f\left(\frac{1}{2}\right)}$. If $\frac{1}{f\left(\frac{1}{2}\right)}<\frac{2}{f(1)}$, which is true if $f(\cdot)$ is concave from $\frac{1}{2}$ to 1 , then $\left(\frac{1}{f\left(\frac{1}{2}\right)}, \frac{2}{f(1)}\right)$ is a range of $k_{2}$ such that the PFR equilibrium exists but the full contribution equilibrium does noteven when full exclusion is possible. Hence, in this dynamic setting with religious capital, allowing free-riding is necessary in some conditions even if exclusion is costless.

Comparing the conditions in Claims 1 and 2, we see that exclusion makes it easier to induce contributions from high capital adults than without exclusion as in the first claim 
because $\frac{1}{f\left(\frac{1}{2}\right)}<\frac{1}{f\left(\frac{1}{2}\right)-f\left(\frac{n-1}{2 n}\right)}$. However, in equilibrium, the ability to exclude does not impact the child's decision to contribute. Thus, if the partial free-rider equilibrium exists in the case with no exclusion (Section 4.2), it will also exist in the case with exclusion (this subsection), though the opposite is not necessarily true. More importantly, we see the same logic from Section 4.2 at work. If children have low capital then they will not contribute, while the high capital adults will contribute. Again, the children must be allowed to free-ride in order for the group to continue through time.

We also learn a deeper point about religious capital formation. Claim 2 establishes that even if full exclusion is possible, so long as some potential contributors (i.e., the children) have sufficiently low capital, then the religious group will still have to allow some free-riding in order for those individuals with very low religious capital to form higher religious capital. This finding demonstrates the fundamental role of religious capital formation and strategic management of free-riding in religious group survival. Free-riding is crucial for the group to continue even if free-riders could be perfectly excluded. If nobody ever forms high capital so that all adults have capital $k_{1}$, then no adults will contribute, no religious good will be produced, and the group will not continue into future periods. Allowing some members to free-ride is necessary for the group to survive over time, but having some contributors is necessary for the group to exist at all at a given point in time.

\subsection{Stigma-screening with Religious Capital Formation}

I now show how the idea that successful groups must allow free-riding is compatible with Iannaccone's $(1992 ; 1994)$ stigma-screening theory. To examine stigma-screening in a context of religious capital formation, we need to again assume that free-riders are not easily identified and excluded (else there is no need to impose a stigmatizing cost). In the basic model above, all children who consume the religious good become high capital adults, so that allowing the free-riders to ride for free was a riskless investment from the group's point of view. In real life, however, not all individuals exposed to the religious good end up becoming high capital adults. Instead, any given individual $i$, conditional on exposure to the religious good, might only form high religious capital with some probability $\alpha_{i}, 0 \leq \alpha_{i} \leq 1$. Moreover, individuals

might differ in their capital formation probabilities, e.g., $\alpha_{i} \neq \alpha_{j}$ for some $i$ and $j$. Some 
individuals have stronger family religious ties, more friends within the religious group, or a personality conducive to the social nature of religion. These differences create a role for stigma-screening because now the free-riders are a risky investment, and the group may want to screen out those free-riders who are less likely to form high capital. By screening out the unwanted types, the base value of the religious good will increase, and by allowing the preferred free-riders to join, the group will survive through time.

To account for these considerations, I extend the basic model in three ways. First, suppose that the group can choose a stigmatizing behavior. By assumption, this behavior does not contribute to production of the religious good, but it does impose a direct cost $b \geq 0$ on an individual who joins the group because, as described by Iannaccone (1992; 1994), it decreases the utility from secular activities. This fixed cost $b$ simplifies the more subtle stigma process modeled by Iannaccone, but has the same effect. Second, and consistent with the original theory, assume that the group excludes based only on compliance with the observable stigmatizing behavior and not on contribution levels, which are assumed to be unobservable due to excessive monitoring costs. Third, assume that there are two types of children born each period. While all $n$ children born in $t$ begin with capital $k_{1}$, only $y$, $0 \leq y \leq n$, of them can form high religious capital if exposed to the religious good. Each of these $y$ children have $a_{i}=a, 0<a<1$. The other $n-y$ children have $a_{i}=0$. As is common in Bayesian games an in keeping with the rational addiction setting, each child knows her own type, but the group does not observe the child's type.

To keep the specification simple, assume that if $y^{\prime}$ of the $y a$-type children join, then exactly $x, 0 \leq x \leq y^{\prime}$ of them form high capital, where $x$ is the integer nearest $a y^{\prime}$. In other words, an $a$-type child who joins knows that there is a $a$ probability that she is one of the $x$ individuals who will have high capital in the next period. Although the exact number of individuals who form high capital is known after the decision to join is made, the acquisition of religious capital is probabilistic in the sense that the identities of which children form high capital are not known a priori by the individual or group.

We are interested in the conditions under which the following "separating" equilibrium 11

\footnotetext{
${ }^{11} \mathrm{~A}$ separating equilibrium is a game theoretic equilibrium in which players of one type choose a different strategy than players of another type, thereby allowing otherwise indistinguishable types to be distinguished
} 
exists: all high capital adults join and contribute, all low capital adults do not join or contribute, all $a$-type children join and do not contribute, and all 0-type children do not join or contribute.

Consider a high capital adult's decision. Joining at cost $b$ and contributing is better for a high capital adult $i$ than joining and not contributing in time period $t$ if

$$
\begin{aligned}
k_{2} f\left(\frac{x}{x+y}\right)-1-b & \geq k_{2} f\left(\frac{x-1}{x+y}\right)-b \Rightarrow \\
k_{2} & \geq \frac{1}{f\left(\frac{x}{x+y}\right)-f\left(\frac{x-1}{x+y}\right)} .
\end{aligned}
$$

The $\frac{x}{x+y}$ term comes from $x$ high capital contributing adults and $y$ low capital non-contributing children. The high capital adult must also prefer joining and contributing to not joining at all:

$$
\begin{gathered}
k_{2} f\left(\frac{x}{x+y}\right)-1-b \geq 0 \Rightarrow \\
k_{2} f\left(\frac{x}{x+y}\right)-1 \geq b .
\end{gathered}
$$

The low capital adult must prefer not joining to joining and contributing:

$$
\begin{aligned}
& 0>k_{1} f\left(\frac{x+1}{x+y}\right)-1-b \Rightarrow \\
& b>k_{1} f\left(\frac{x+1}{x+y}\right)-1 .
\end{aligned}
$$

The low capital adult must also prefer not joining to joining and not contributing:

$$
\begin{aligned}
& 0>k_{1} f\left(\frac{x}{x+y}\right)-b \Rightarrow \\
& b>k_{1} f\left(\frac{x}{x+y}\right) .
\end{aligned}
$$

The $a$-type child will join and contribute as an adult if she forms high capital but not join or contribute as an adult if she does not form high capital. Her expected payoff of by their actions. The equilibrium of interest here is appropriately called separating because the children choose different actions depending on their types. The $a$-type children choose to join, and the 0 -type children do not join. 
joining and not contributing must be greater than joining and contributing:

$$
\begin{aligned}
& k_{1} f\left(\frac{x}{x+y}\right)-b+a\left(k f\left(\frac{x}{x+y}\right)-1-b\right) \\
\geq & k_{1} f\left(\frac{x+1}{x+y}\right)-1-b+a\left(k_{2} f\left(\frac{x}{x+y}\right)-1-b\right) \Rightarrow \\
k_{1} \leq & \frac{1}{f\left(\frac{x+1}{x+y}\right)-f\left(\frac{x}{x+y}\right)} .
\end{aligned}
$$

Joining and not contributing must also be better than not joining:

$$
\begin{aligned}
k_{1} f\left(\frac{x}{x+y}\right)-b+a\left(k_{2} f\left(\frac{x}{x+y}\right)-1-b\right) & \geq 0 \Rightarrow \\
k_{1} f\left(\frac{x}{x+y}\right)+a\left(k_{2} f\left(\frac{x}{x+y}\right)-1\right) & \geq b(1+a) \Rightarrow \\
k_{1} f\left(\frac{x}{x+y}\right)+a k_{2} f\left(\frac{x}{x+y}\right)-a & \geq b(1+a) \Rightarrow \\
\frac{k_{1}}{1+a} f\left(\frac{x}{x+y}\right)+\frac{a}{1+a} k_{2} f\left(\frac{x}{x+y}\right)-\frac{a}{1+a} & \geq b
\end{aligned}
$$

Finally, the 0-type child in this equilibrium will not join or contribute as an adult. Her expected payoff to not joining must be greater than joining and not contributing:

$$
\begin{aligned}
& 0>k_{1} f\left(\frac{x}{x+1+y}\right)-b \Rightarrow \\
& b>k_{1} f\left(\frac{x}{x+1+y}\right) .
\end{aligned}
$$

This expected payoff must also be greater than that of joining and contributing:

$$
\begin{aligned}
& 0>k_{1} f\left(\frac{x+1}{x+1+y}\right)-1-b \Rightarrow \\
& b>k_{1} f\left(\frac{x+1}{x+1+y}\right)-1 .
\end{aligned}
$$

Conditions (3)-(10) are necessary and sufficient for the equilibrium to exist in $t$. They have natural interpretations. Condition (3) says that for high capital adults to contribute, their religious capital must be sufficiently large, while according to condition (7) a-type children must have sufficiently low capital to not contribute. Conditions (4) and (8) say that the strictness cost must be sufficiently small so that the high capital adults and the $a$-type children are willing to join. Conditions (5), (6), (9), and (10) say that the strictness 
cost must also be sufficiently large so that low capital adults and 0-type children will not join. As in other screening scenarios, the screening cost must be large enough to screen out the unwanted types but not too large to screen out the wanted types. ${ }^{12}$

To show that this equilibrium exists, we need only show that these conditions can be simultaneously met. This is easily accomplished by example. Suppose $k_{1}=0$ so that each child is born with no capital. Then (7) is trivially met for any increasing $f(\cdot)$, and (5), (6), (9), and (10) are met for any $b>0$. (3), (4), and (8) will now hold if $k_{2}$ is large and $b>0$ sufficiently small. Of course, there are many parameter combinations that will satisfy the conditions. As long as $k_{1}$ is sufficiently small, $k_{2}$ is sufficiently large, and $b$ is in the appropriate medium range, this separating equilibrium will exist.

Claim 3 A separating equilibrium with partial free-riding exists when conditions (3)(10) are met.

From conditions (5), (6), (9), and (10) it is clear that the separating equilibrium does not exist without the group's rules that generate the behavioral cost $b$ of membership. Without such rules (i.e., $b=0$ ), the partial free-rider equilibrium in the multi-type setting is a "pooling" one akin to that in Section 4.2 in which both children types join but where only ay of the $n$ children form high religious capital. The propositions in Section 3 arise from comparing the separating and pooling equilibria. With ay children expected to form high religious capital in any given period, we expect to observe ay contributions and $a y+y$ members in any period of the separating equilibrium. This yields average contributions of $\frac{a y}{a y+y}=\frac{a}{a+1}$. In the "non-strict" pooling equilibrium, the average contribution is $\frac{a y}{2 n}$, which is less than $\frac{a}{a+1}$ because $y \leq n$. Thus, consistent with Proposition 1 , the model predicts that strict churches with costly behavioral requirements will have higher average contributions than non-strict churches.

The model also predicts a lower degree of skewness in strict churches' contributions than in non-strict churches as predicted by Proposition 2. One manifestation of skewness is when there are fewer people contributing above the average contribution than there are contributing below the average contribution. The more positively skewed the distribution, the

\footnotetext{
${ }^{12}$ This medium level screening cost is similar to that in Spence's (1973) original examination of education as a screening device.
} 
more members are contributing less than the mean contribution level than are contributing above the mean. In the separating equilibrium with average contribution $\frac{a y}{a y+y}$, there are $a y+y$ non-contributors (below the mean) and ay contributors (above the mean). In the pooling $(b=0)$ equilibrium with average $\frac{a y}{2 n}$, there are the same number of contributors but a much larger number of non-contributors. Thus, the pooling equilibrium's distribution of contributions is more skewed than the separating equilibrium. The model predicts that the distribution of contributions in non-strict churches will be more skewed than in strict churches.

Finally, consistent with Proposition 3, the model predicts that free-riders of a certain kind are welcomed in strict churches. For the equilibrium to exist, the strictness cost is set so that the $a$-type children are screened into the group, and the 0-type children are screened out of the group. The $a$-type children are screened into the group because they play a crucial role in facilitating the continuance of the church.

\section{Discussion}

This paper argues for a dynamic generalization of Iannaccone's original stigma-screening theory. Religious contributors are not born but are produced though the process of religious capital formation. To gain future contributors, a religious group must allow some individuals to ride for free while they form religious capital. Because this capital formation process is costly and risky, a group can choose, via the requirement of strict behavioral codes, to screen out those individuals less likely to form religious capital. Thus, stigma-screening can be understood as a way to improve the return on a church's religious capital investment.

One insight from this theory is that strict churches rationally allow a degree of heterogeneity in their memberships. This heterogeneity is limited because certain individuals are screened out due to the stigmatizing behavioral requirements, yet it is still there in a form that serves an important institutional purpose. The welcomed free-riders are potential future contributors, and their free-riding is seen as an investment by the church.

A second insight is that the fostering of heterogeneous memberships does not undermine the stigma-screening logic. Instead, both methods combine to foster both high contribu- 
tions and high religious capital formation. It is simplest to think of allowing free-riders as independent of the stigma-screening. Dynamically allowing free-riders is necessary when individuals are born with no capital and must form it before contributing, and this is so even if the religious goods are perfectly excludable. Stigma-screening is an independent mechanism to increase contribution levels when there are different types of individuals. A useful comparison is a firm hiring a new employee. The firm will screen potential applicants when some types of applicants have the potential to be more productive than others, but it will also use its own resources to invest in that worker's firm-specific human capital once hired. The theory presented here develops this idea in the context of collectively produced religious goods.

This revised theory suggests a rethinking of the term free-rider in the context of religion. Just exactly what type of behavior constitutes free-riding behavior? The stigma-screening process screens out certain types of free-riders but screens in other types. These desirable types do in fact free-ride temporarily, but they are welcomed in the hope that they do not free-ride forever. It is contrary to the essence of the term free-rider to use that term to describe individuals who are investments by the church. We should rethink what constitutes religious free-riding and distinguish among the different types of free-riding. Acknowledging the difference in individuals' ability to form religious capital and variation in acceptance of those individuals by the church is a step in this direction.

The institutional impulse to allow free-riding can also extend to other, non-religious, settings. Iannaccone (1992) explains that the stigma-screening process helps us understand not just the behavior of strict churches but also that of communes and collectives because they all produce social goods yet have difficulties measuring different types of contributions. To the extent that individuals in these other settings must have high human capital tied to the group in order to contribute, the revised stigma-screening logic will hold as well.

Of course, actual groups exist in richer environments than that of the abstract model presented in Section 4, and they will often have developed other means by which to moderate the degree of free-rider investment. The LDS Church mentioned earlier again serves as a useful example. As explained by McBride (forthcoming), the LDS Church allows many noncontributing individuals to consume various socially produced goods - such as the enjoyment 
of worship services, use of Church-produced printed materials, home visits, certain forms of ecclesiastical support, certain rituals - and many of these are easy to exclude. Many of these goods foster religious capital formation, yet the LDS Church also excludes some of the most important religious goods to contributors - access to certain rituals, certain ecclesiastical positions, etc. This is a case where the group openly allows free-riders to consume some but not all goods, and by so doing it both allows and limits free-riding. Future theoretical work should examine the conditions under which a religious group offers some but not all benefits to free-riders.

Future work has many other avenues to pursue. One direction is to study why some churches stigma-screen while others do not. This paper does not offer a theory of why some but not all churches choose to be strict. Claim 3 takes as given that some churches set $b>0$ while others set $b=0$. A more general model would account for the group's preferences and would benefit from a consideration of various factors relevant to religious organizations. Montgomery (1996), for example, examines how the evolution of a church's strictness depends not only on religious capital formation but also on the "voice" expressed by members. The model should also explain why some groups that do not appear to stigmascreen, such as megachurches, are very successful in the religious marketplace. Another avenue involves the examination of religious production functions. The simplified model in this paper considered only average contributions as relevant for religious good production because this is the important factor that generates the free-rider problem. Including the level of contributions in the production function has the potential to yields still further insights into our understanding of religious good production. Still another line of work will look at how groups with strong motivations for membership growth handle the free-rider problem. The model here discussed group survival and not growth per se. Future work along these lines will lead to the development of a more comprehensive theory of religious free-riding.

\section{References}

[1] Becker, Gary, Kevin Murphy. 1988. "A Theory of Rational Addiction." Journal of Political Economy 96: 675-700. 
[2] Berger, Peter. 1967 [1990]. The Sacred Canopy: Elements of a Sociological Theory of Religion. New York: Anchor Books.

[3] Bruce, Steve. 2002. God is Dead: Secularization in the West. Oxford: Blackwell Publishing.

[4] Chaves, Mark. 1995. "On the Rational Choice Approach to Religion." Journal for the Scientific Study of Religion 34: 98-104.

[5] Demerath, N.J. 1995. "Rational Paradigms: A-Rational Religion, and the Debate over Secularization." Journal for the Scientific Study of Religion 34: 105-112.

[6] Ekelund, Robert, Jr. et al. 1996. Sacred Trust: The Medieval Church as an Economic Firm. New York: Oxford University Press.

[7] Ellison, Christopher. 1995. "Rational Choice Explanations of Individual Religious Behavior: Notes on the Problem of Social Embeddedness." Journal for the Scientific Study of Religion 34: 89-97.

[8] Fan, C. Simon. Forthcoming. "Religious Participation and Children's Education: A Social Capital Approach." Journal of Economic Behavior and Organization.

[9] Hoge, Dean, Charles Zech, Patrick McNamara, Michael Donahue. 1996. Money Matters: Personal Giving in American Churches. Louisville, KY: Westminster John Knox Press.

[10] Iannaccone, Laurence. 1990. "Religious Practice: A Human Capital Approach." Journal for the Scientific Study of Religion 29: 297-314.

[11] Iannaccone, Laurence. 1992. "Sacrifice and Stigma: Reducing Free-riding in Cults, Communes, and Other Collectives." Journal of Political Economy 100: 271-291.

[12] Iannaccone, Laurence. 1994. "Why Strict Churches are Strong." American Journal of Sociology 99: 1180-1211.

[13] Iannaccone, Laurence. 1995. "Voodoo Economics? Reviewing the Rational Choice Approach to Religion." Journal for the Scientific Study of Religion 34: 76-88.

[14] Iannaccone, Laurence. 1997. "Skewness Explained: A Rational Choice Model of Religious Giving." Journal for the Scientific Study of Religion 36: 141-157.

[15] Iannaccone, Laurence. 1998. "An Introduction to the Economics of Religion." Journal of Economic Literature XXXVI: 1465-1496.

[16] Iannaccone, Laurence, Daniel Olson, Rodney Stark. 1995. "Religious Resources and Church Growth." Social Forces 74: 705-731. 
[17] Kelley, Dean. 1972 [1986]. Why Conservative Churches are Growing: A Study in Sociology of Religion with a New Preface for the ROSE Edition. Macon, GA: Mercer University Press.

[18] McBride, Michael. 2007. "Religious Pluralism and Religious Participation: A Game Theoretic Analysis." Department of Economics, University of California, Irvine.

[19] McBride, Michael. Forthcoming. "Club Mormon: Free-riders, Monitoring, and Exclusion in the LDS Church." Rationality and Society.

[20] Montgomery, James. 1996. "Dynamics of the Religious Economy: Exit, Voice, and Denominational Secularization." Rationality and Society 8: 81-110.

[21] Miller, Kent. 2002. "Competitive Strategies of Religious Organizations." Strategic Management Journal 23: 435-456.

[22] Olson, Daniel, Paul Perl. 2001. "Variations in Strictness and Religious Commitment Within and Among Five Denominations." Journal for the Scientific Study of Religion 40: $757-764$.

[23] Olson, Daniel, Paul Perl. 2005. "Free and Cheap Riding in Strict, Conservative Churches." Journal for the Scientific Study of Religion 44: 123-142.

[24] Roberts, Keith. 2004. Religion in Sociological Perspective. Belmont, CA: Wadsworth/Thomson Learning.

[25] Sherkat, Darren, Christopher Ellison. 1999. "Recent Developments and Current Controversies in the Sociology of Religion." Annual Review of Sociology 25: 363-394.

[26] Spence, Michael. 1973. "Job Market Signaling." Quarterly Journal of Economics 87: 355-374.

[27] Stark, Rodney, Roger Finke. 2000. Acts of Faith: Explaining the Human Side of Religion. Berkeley, CA: University of California Press.

[28] Stark, Rodney, Laurence Iannaccone. 1997. "Why the Jehovah's Witnesses Grow so Rapidly: A Theoretical Application." Journal of Contemporary Religion 12: 133-157.

[29] Thumma, Scott, Dave Travis, Warren Bird. 2005. "Megachurches Today 2005: Summary of Research Findings." Hartford Institute for Religion Research. Available at (http://hirr.hartsem.edu/megachurch/megastoday2005summaryreport.pdf).

[30] Thumma, Scott. 2006. "The Business of Megachurches." Presented at the 2006 Association for the Study of Religion, Economics, and Culture Conference. 
[31] Tomer, John. 2001. "Addictions are not rational: A Socio-economic Model of Addictive Behavior." Journal of Socio-Economics 33: 243-261.

[32] von der Ruhr, Marc, Joseph Daniels. 2006. "A Survey of Models to Explain the Success of "Megachurches:" the Market for Religious Affiliation." Presented at the 2006 Association for the Study of Religion, Economics, and Culture Conference.

[33] von der Ruhr, Marc, Thomas Reynolds. 2006. "Bridging to Bond: An Application of Economic Theory to Studying Megachurches, Conversion, and the Impact of Spiritual Capital." Presented at the 2006 Association for the Study of Religion, Economics, and Culture Conference.

[34] Warner, R. Stephen. 1993. "Work in Progress Toward a New Paradigm for the Sociological Study of Religion in the United States." American Journal of Sociology 98: 1044-1093.

[35] Yamane, David. 1997. "Secularization on Trial: In Defense of a Neosecularization Paradigm." Journal for the Scientific Study of Religion 36: 109-122.

[36] Young, Lawrence., ed. 1997. Rational Choice Theory and Religion: Summary and Assessment. New York: Routledge. 
Table 1: Classification of Some Religious Groups by Strictness

\begin{tabular}{|c|c|}
\hline Ultra-strict & $\begin{array}{l}\text { Amish } \\
\text { Hare Krishnas } \\
\text { Hasidic Jews }\end{array}$ \\
\hline Strict & $\begin{array}{l}\text { Assemblies of God } \\
\text { Jehovah's Witnesses } \\
\text { Latter-day Saints } \\
\text { Nazarenes } \\
\text { Orthodox Jews }\end{array}$ \\
\hline Conservative & $\begin{array}{l}\text { Conservative Jews } \\
\text { Missouri Lutherans } \\
\text { Seventh-day Adventists } \\
\text { Southern Baptist Convention }\end{array}$ \\
\hline Moderate & $\begin{array}{l}\text { American Baptists } \\
\text { Lutherans }\end{array}$ \\
\hline Liberal & $\begin{array}{l}\text { Episcopalians } \\
\text { Methodists } \\
\text { Presbyterians }\end{array}$ \\
\hline Ultra-liberal & $\begin{array}{l}\text { Reform Judaism } \\
\text { Unitarian Universalists } \\
\text { United Church of Christ }\end{array}$ \\
\hline
\end{tabular}

Notes: This classification is adapted from Ch. 8 of Stark and Finke (2000). 


\section{Table 2: Financial Contributions by Religious Group}

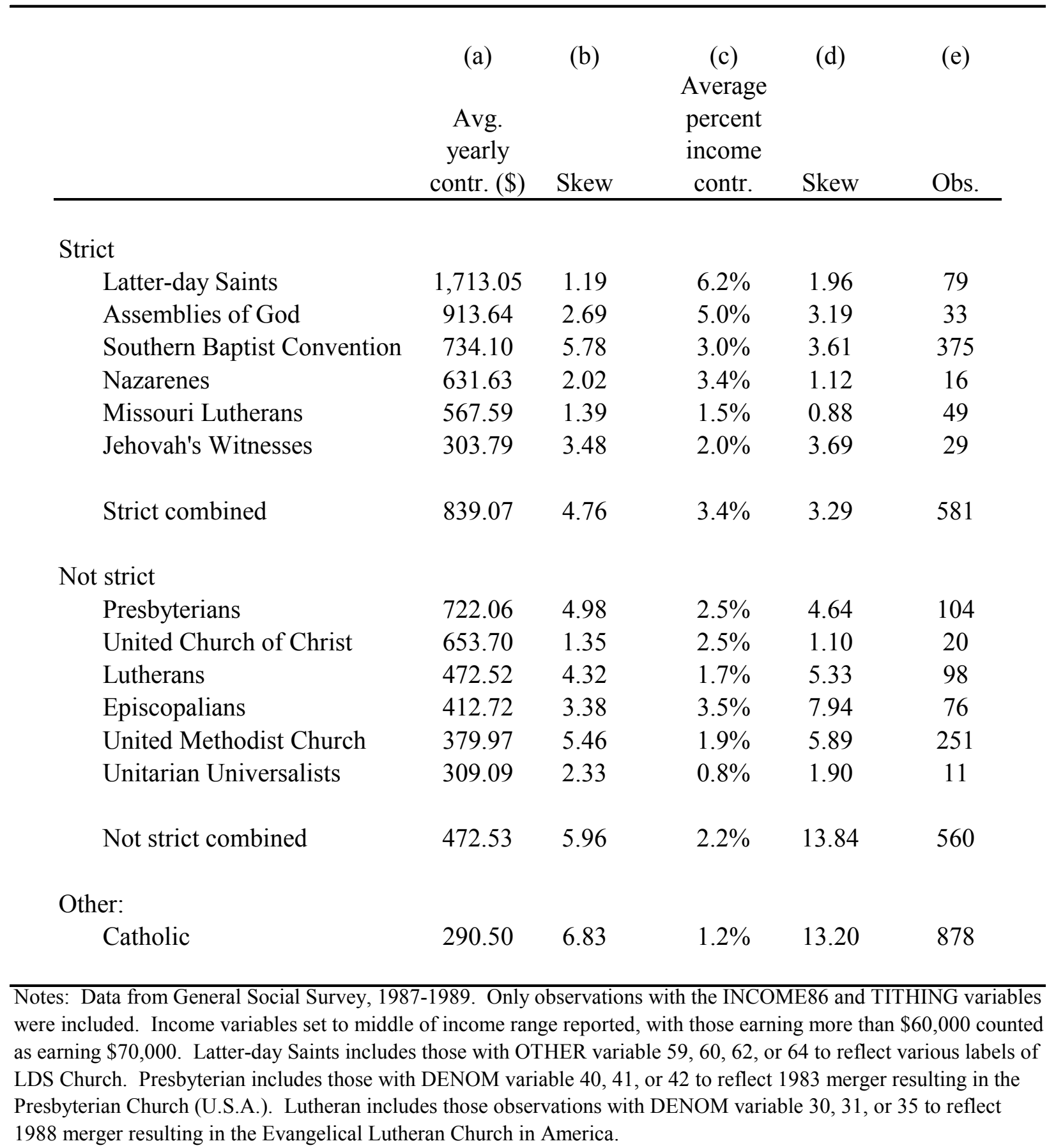




\section{Table 3: Members' Self-reported Grades of own Religious Group}

(a)

Average self-

reported (b)

Obs.

Strict

Latter-day Saints

Jehovah's Witnesses

Assemblies of God

Nazarenes

Southern Baptist Convention

Missouri Lutherans

Strict combined

Not strict

United Church of Christ

Lutherans

United Methodist Church

Episcopalians

Presbyterians

Unitarian Universalists

Not strict combined
3.81

3.80

3.50

3.00

2.99

2.95

3.19

3.11

2.97

2.86

2.71

2.60

2.33

2.82

Other:

Catholic
159

22

10

6

2

85

19

144

9

31

65

21

30

3

227

Notes: Data from General Social Survey, 1988. The question asked, "Using the school grading system of A, B, C, D, and F for Fail, how do you rate your church or religious group in meeting your spiritual needs?" A is counted as 4, B as 3, C as 2, D as 1, and F as 0. Latter-day Saints includes those with OTHER variable 59, 60, 62, or 64 to reflect various labels of LDS Church. Presbyterian includes those with DENOM variable 40, 41, or 42 to reflect 1983 merger resulting in the Presbyterian Church (U.S.A.). Lutheran includes those observations with DENOM variable 30, 31, or 35 to reflect 1988 merger resulting in the Evangelical Lutheran Church in America. 